\title{
A novel proposed grading system for cerebellar arteriovenous malformations
}

\author{
*Peyton L. Nisson, BS, ${ }^{1,2}$ Salman A. Fard, MD, ${ }^{1}$ Christina M. Walter, MS, ${ }^{3}$ \\ Cameron M. Johnstone, AB, ${ }^{3}$ Michael A. Mooney, MD, ${ }^{4}$ Ali Tayebi Meybodi, MD, ${ }^{4}$ \\ Michael Lang, MD, ${ }^{4}$ Helen Kim, PhD, ${ }^{2}$ Heidi Jahnke, MSN,${ }^{4}$ Denise J. Roe, DrPH, MS, ${ }^{5}$ \\ Travis M. Dumont, MD, ${ }^{3}$ G. Michael Lemole Jr., MD, ${ }^{3}$ Robert F. Spetzler, MD, ${ }^{4}$ and \\ Michael T. Lawton, MD2,4
}

${ }^{1}$ College of Medicine, University of Arizona, Tucson, Arizona; '2Department of Neurosurgery, University of California, San Francisco, California; ${ }^{3}$ Division of Neurosurgery, Banner-University Medical Center, Tucson, Arizona; ${ }^{4}$ Department of Neurosurgery, Barrow Neurological Institute, Phoenix, Arizona; and ${ }^{5}$ Epidemiology and Biostatistics, College of Public Health, University of Arizona, Tucson, Arizona

OBJECTIVE The objective of this study was to evaluate the existing Spetzler-Martin (SM), Spetzler-Ponce (SP), and Lawton-Young (LY) grading systems for cerebellar arteriovenous malformations (AVMs) and to propose a new grading system to estimate the risks associated with these lesions.

METHODS Data for patients with cerebellar AVMs treated microsurgically in two tertiary medical centers were retrospectively reviewed. Data from patients at institution 1 were collected from September 1999 to February 2013, and at institution 2 from October 2008 to October 2015. Patient outcomes were classified as favorable (modified Rankin Scale [mRS] score 0-2) or poor (mRS score 3-6) at the time of discharge. Using chi-square and logistic regression analysis, variables associated with poor outcomes were assigned risk points to design the proposed grading system. The proposed system included neurological status prior to treatment (poor, +2 points), emergency surgery $(+1$ point), age $>60$ years $(+1$ point), and deep venous drainage (deep, +1 point). Risk point totals of $0-1$ comprised grade 1, 2-3 grade 2, and 4-5 grade 3 .

RESULTS A total of 125 cerebellar AVMs of 1328 brain AVMs were reviewed in 125 patients, 120 of which were treated microsurgically and included in the study. With our proposed grading system, we found poor outcomes differed significantly between each grade $(p<0.001)$, while with the SM, SP, and LY grading systems they did not $(p=0.22, p=0.25$, and $p=1$, respectively). Logistic regression revealed grade 2 had 3.3 times the risk of experiencing a poor outcome $(p=$ 0.008 ), while grade 3 had 9.9 times the risk $(p<0.001)$. The proposed grading system demonstrated a superior level of predictive accuracy (area under the receiver operating characteristic curve [AUROC] of 0.72) compared with the SM, SP, and $L Y$ grading systems (AUROC of $0.61,0.57$, and 0.51 , respectively).

CONCLUSIONS The authors propose a novel grading system for cerebellar AVMs based on emergency surgery, venous drainage, preoperative neurological status, and age that provides a superior prognostication power than the formerly proposed SM, SP, and LY grading systems. This grading system is clinically predictive of patient outcomes and can be used to better guide vascular neurosurgeons in clinical decision-making.

https://thejns.org/doi/abs/10.3171/2018.12.JNS181677

KEYWORDS cerebellar; arteriovenous malformations; grading system; risk assessment; prognosis; outcomes; vascular disorders

ABBREVIATIONS AUROC = area under the receiver operating characteristic curve; $\mathrm{AVM}=$ arteriovenous malformation; $\mathrm{Cl}=\mathrm{confidence}$ interval; $\mathrm{GKS}=\mathrm{Gamma}$ Knife surgery; LY = Lawton-Young; mRS = modified Rankin Scale; OR = odds ratio; PoNS = postoperative neurological status; PrNS = preoperative neurological status; SM = Spetzler-Martin; SP = Spetzler-Ponce.

SUBMITTED June 11, 2018. ACCEPTED December 3, 2018.

INCLUDE WHEN CITING Published online March 8, 2019; DOI: 10.3171/2018.12.JNS181677.

* P.L.N. and S.A.F. contributed equally to this work. 


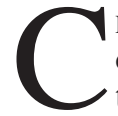
EREBELLAR arteriovenous malformations (AVMs) comprise $10 \%-15 \%$ of all intracranial AVMs and the majority $(70 \%)$ of infratentorial AVMs. ${ }^{11,36} \mathrm{De}-$ spite being a minority of AVM cases, cerebellar AVMs represent an important subgroup of patients due to their higher risk for morbidity and mortality than supratentorial AVMs. ${ }^{47}$ Cerebellar AVMs are unique in their natural history, having a greater annual risk for rupture and being more technically challenging to resect because of their close proximity to the brainstem and vital blood supply. ${ }^{1,2,15,35,46,47}$ In terms of angioarchitecture, they possess a proclivity for deep venous drainage, adding another complicating factor to their management. ${ }^{1,2}$

Given the risk for hemorrhagic stroke, resection remains the gold standard for treating brain AVMs. ${ }^{4,48}$ Compared to the other modalities available, surgery averages $95.9 \%$ complete obliteration versus $22.1 \%$ for endovascular treatment and $67.4 \%$ for radiosurgery. ${ }^{4}$ Still, unique benefits afforded from these alternatives include the ability to reach complex, poorly accessible lesions and being a less invasive option for poor surgical candidates. These alternatives are typically favored for Spetzler-Martin (SM) grade IV-V lesions, which have higher rates of perioperative complications and lower rates of complete removal..$^{22,23}$

However, in light of the unique natural history and angioarchitectural characteristics of cerebellar AVMs, their management is also distinct from their supratentorial counterparts, requiring a more aggressive treatment strategy. ${ }^{1,2}$ Despite a growing body of scientific literature, a continued challenge has been predicting the outcomes of these lesions. ${ }^{35}$ Accurate risk stratification is important when considering surgical therapy, in terms of both patient decision-making and treatment strategy. A previous study by Rodríguez-Hernández et al. ${ }^{35}$ found the most widely used grading system (the SM grading system) did not reliably convey the risk associated with treating these lesions.

The objective of this study was to develop a powerful, yet simple and specific grading system to better guide vascular neurosurgeons' decision-making and patient counseling for cerebellar AVMs, using the largest patient database reported in the US to date. ${ }^{35,46}$

\section{Methods \\ Patient Population}

At two tertiary medical academic centers (Barrow Neurological Institute and the University of California, San Francisco), data were retrospectively collected on patients with surgically treated cerebellar AVMs. IRB approval was obtained from each institution to conduct a retrospective study. Waivers of consent to access patient data were obtained from each institution separately. Sixty patients were treated between September 1999 and February 2013 at institution 1 and 65 patients between October 2008 and October 2015 at institution 2. Four patients were excluded who presented to either institution but did not undergo microsurgery; 2 underwent Gamma Knife surgery (GKS) only, 1 embolization only, and 1 GKS and embolization. Another patient did not have neurological outcome assessment available in the medical chart, leaving a total of 120 subjects included in the study (Fig. 1).

\section{Data Collection}

For each patient, demographic features, presence of hemorrhage at presentation, whether patients were treated emergently, radiographic and angiographic features of the lesion, treatments performed, preoperative neurological status (PrNS), postoperative neurological status (PoNS), and most recent follow-up neurological status were recorded. Postoperative AVM obliteration status (using postoperative angiography) was also collected. Patient neurological status was defined by modified Rankin Scale (mRS) scores that were categorized into two groups: $\mathrm{mRS}$ scores $<3$ were considered a favorable neurological status, and scores of 3-6 were considered a poor neurological status. The PrNS was derived from the mRS score that was either calculated from objective information of the patient's neurological status or recorded directly from the medical chart closest to the time of the operation. PoNS was calculated using the same method but at the time of discharge following surgical treatment. The mRS scores were retrieved from the medical record by independent research faculty members from each respective institution.

Eloquence was defined as any cerebellar AVM located in deep nuclei or cerebellar peduncles. Venous drainage was considered deep, except for cerebellar hemispheric veins draining directly into the straight sinus or transverse sinus. Both of these definitions followed the convention of the originally proposed definition of Spetzler and Martin. ${ }^{39}$

"Hemorrhage at presentation" was recorded for any patients who initially presented with a hemorrhage, leading to the discovery of their cerebellar AVM. However, "emergent surgery" was recorded in patients who had a life-threatening hematoma in the posterior fossa and underwent emergency surgery. The "hemorrhage at presentation" group did not necessarily include all patients treated with emergency surgery as some patients may have initially presented without hemorrhage, but then later experienced hemorrhage and were taken to the operating room emergently.

\section{Statistical Analysis}

Statistical analysis was performed using STATA software (version 14, StataCorp LP). The independent t-test was used to compare the means of continuous, parametric variables. If the continuous data were nonparametric, medians were compared using a Wilcoxon rank-sum test. The chi-square test was used to compare categorical variables, and if the expected frequency was less than 6, then the Fisher exact test was used. The grading systems (SM, Spetzler-Ponce [SP], Lawton-Young [LY], and proposed) were also assessed using univariate and multivariate logistic regression along with the area under the receiver operating characteristic curve (AUROC). A p value $\leq 0.05$ was considered significant in all statistical analyses.

\section{Literature Review}

A review of the MEDLINE database (National Library of Medicine) was performed in October 2018 for articles published in English between October 1952 and October 

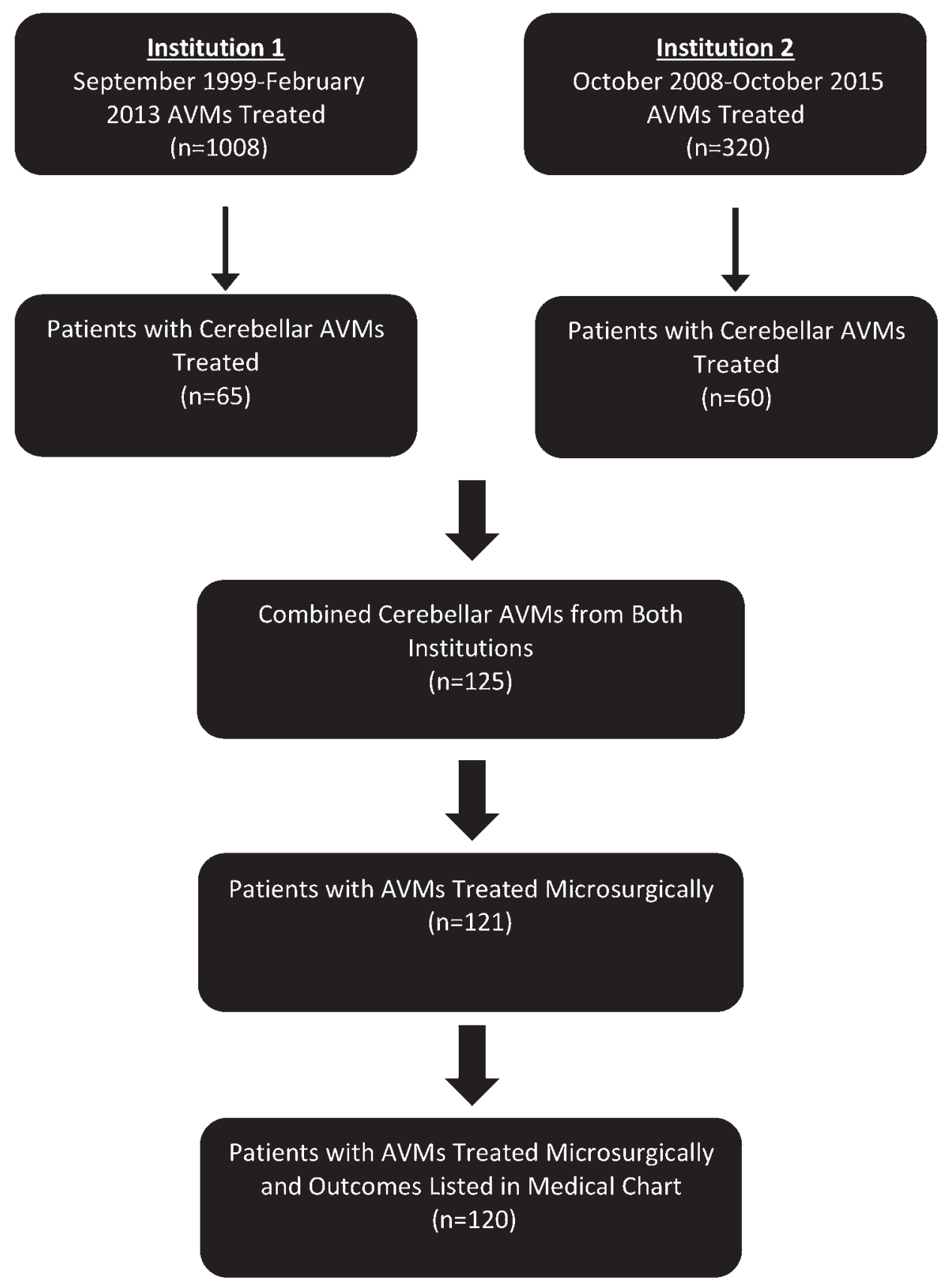

FIG. 1. Flowchart of patient selection for study inclusion.

2018. Search terms included "cerebellar arteriovenous malformation," "cerebellum arteriovenous malformation," and "infratentorial arteriovenous malformation." We reviewed search results to assess the relevance of existing grading systems for cerebellar AVMs. Articles related to brainstem AVMs and case reports were excluded. References from eligible articles were reviewed to locate other articles of interest.

\section{Results}

A total of 120 patients with 120 cerebellar AVMs were included in the study. The mean age of the patients treated was 44.7 years (range $4.3-83$ years); $40 \%$ of the patients were male. A total of 36 patients had a cerebellar AVM size $\geq 3 \mathrm{~cm}$ (range 0.3-9.4 cm, mean $2.3 \mathrm{~cm}$; Table 1). Complete resection was achieved in 89.9\% (107/119) of patients. One patient did not undergo follow-up angiography after surgery, so obliteration could not be confirmed.

The majority of patients $(66 / 120,55.0 \%)$ were in a poor neurological state following microsurgical resection at the time of discharge. Thirty-nine (61.9\%) of the 63 patients in favorable PrNS remained in a favorable PoNS following treatment; 42 (73.7\%) of 57 patients with a poor PrNS remained in a poor PoNS; 24 (20\%) worsened from their 
TABLE 1. Patient initial presentation summary

\begin{tabular}{|c|c|}
\hline Variable & Value (\%) \\
\hline No. of patients & 120 \\
\hline Mean age, yrs & 45 \\
\hline Age range, yrs & $4.3-83$ \\
\hline Males & $48(40)$ \\
\hline Pediatric patients & $16(13)$ \\
\hline \multicolumn{2}{|l|}{ Ethnicity } \\
\hline White & $67(56)$ \\
\hline Hispanic & $29(24)$ \\
\hline Black & $14(12)$ \\
\hline Other & $10(8)$ \\
\hline Hemorrhage at presentation & $85(71)$ \\
\hline Emergency surgery & $45(38)$ \\
\hline Eloquence & $22(18)$ \\
\hline Associated aneurysm & $40(33)$ \\
\hline \multicolumn{2}{|l|}{ Venous drainage } \\
\hline Superficial & $45(39)$ \\
\hline Deep & $72(62)$ \\
\hline \multicolumn{2}{|l|}{ Location } \\
\hline Cerebellar hemisphere only & $73(62)$ \\
\hline Vermis & $22(19)$ \\
\hline Deep cerebellar nuclei & $19(16)$ \\
\hline Cerebellar peduncle & $3(3)$ \\
\hline Cerebellar tonsil & $1(1)$ \\
\hline Mean AVM size, cm & 2.3 \\
\hline$A V M \geq 3 \mathrm{~cm}$ & $36(30)$ \\
\hline \multicolumn{2}{|l|}{ SM grade } \\
\hline 1 & $29(25)$ \\
\hline II & $47(40)$ \\
\hline III & $31(26)$ \\
\hline IV & $10(9)$ \\
\hline V & $1(1)$ \\
\hline Mean follow-up, yrs & 1.8 \\
\hline Follow-up range, yrs & $0.01-8.61$ \\
\hline
\end{tabular}

PrNS to their PoNS. Fifteen (12.5\%) of those with a poor PrNS improved to a favorable PoNS. There were 3 perioperative deaths $(2.5 \%)$ and 9 deaths $(7.5 \%)$ at the time of the most recent follow-up. Patient mRS scores prior to surgery and at the time of most recent follow-up are available in Supplemental Table 1.

\section{SM, SP, and LY Grading Systems}

When comparing the rate of poor outcomes, no significant difference was found for the SM $(\mathrm{p}=0.22)$, SP ( $0.25)$, and $\mathrm{LY}(\mathrm{p}=1)$ grades using the Fisher exact test and simple logistic regression (SM: odds ratio $[\mathrm{OR}] 1.32, \mathrm{p}=$ 0.17, AUROC $=0.61 ;$ SP: OR $1.23, p=0.46$, AUROC $=$ 0.57; LY: OR 0.97, $\mathrm{p}=0.89, \mathrm{AUROC}=0.51$ ).

\section{Risk Factors for Poor Outcome and Model Development}

To thoroughly assess the risk for poor outcomes associated with each variable recorded in the study, univariate logistic regression was performed. We found a significantly greater risk associated with patients over the age of 60 years $(\mathrm{OR} 2.5, \mathrm{p}=0.04)$, emergency surgery $(\mathrm{OR} 2.2, \mathrm{p}=$ 0.048 ), PrNS (OR 4.6, p < 0.001), and deep venous drainage (OR 2.3, $\mathrm{p}=0.03$ ). All of these variables were then included in the risk-prediction model (Table 2).

Cerebellar AVM size did not correlate with patient outcomes (OR 1.21, $\mathrm{p}=0.64)$ and was not included in the model (Table 2). We found no difference for the mean cerebellar AVM size between those who initially presented with hemorrhage versus those who did not $(\mathrm{p}=$ 0.34 ) or between those with emergency surgery versus those without $(\mathrm{p}=0.59)$. Emergency surgery for small AVMs $(36.6 \%, 30 / 82)$ was nearly identical to that of large AVMs $(36.1 \%, 13 / 36 ; p=0.96)$. Similarly, this was true for those who initially presented with hemorrhage with small $(70.7 \%, 58 / 82)$ versus large $(69.4 \%, 25 / 36)$ cerebellar AVMs $(\mathrm{p}=0.89)$. Multivariate regression analysis revealed only PrNS was significantly associated with poor outcomes $(p=0.001)$. Given this finding, the predictive accuracy of PrNS alone was calculated, which revealed an AUROC value of 0.679 . However, after including the other

TABLE 2. Logistic regression analysis of risk factors for poor outcomes

\begin{tabular}{|c|c|c|c|c|c|c|}
\hline \multirow[b]{2}{*}{ Variable } & \multicolumn{3}{|c|}{ Univariate Logistic Regression } & \multicolumn{3}{|c|}{ Multivariate Logistic Regression } \\
\hline & OR & $p$ Value & $95 \% \mathrm{Cl}$ & OR & p Value & $95 \% \mathrm{Cl}$ \\
\hline Age ( $\geq 60 \mathrm{yrs})$ & 2.5 & 0.04 & $1.04-6.03$ & 1.6 & 0.34 & $0.59-4.59$ \\
\hline Age & 1.02 & 0.09 & $0.99-1.04$ & & & \\
\hline Sex (female) & 0.6 & 0.18 & $0.28-1.3$ & & & \\
\hline Embolization prior to surgery & 1.3 & 0.45 & $0.64-2.75$ & & & \\
\hline Hemorrhage at initial presentation & 2 & 0.09 & $0.90-4.44$ & & & \\
\hline Emergency surgery & 2.2 & 0.048 & $1-4.7$ & 1.5 & 0.39 & $0.60-3.56$ \\
\hline AVM size & 1 & 1 & $0.76-1.31$ & & & \\
\hline AVM size $\geq 3 \mathrm{~cm}$ & 1.2 & 0.64 & $0.55-2.67$ & & & \\
\hline Eloquence (yes) & 1.7 & 0.4 & $0.49-6.07$ & & & \\
\hline Associated aneurysm & 1.9 & 0.12 & $0.85-4.07$ & & & \\
\hline Deep venous drainage & 2.3 & 0.03 & $1.07-4.88$ & 1.9 & 0.13 & $0.82-4.27$ \\
\hline PrNS & 4.6 & $<0.001$ & $2.09-9.91$ & 3.82 & 0.001 & $1.67-8.74$ \\
\hline
\end{tabular}




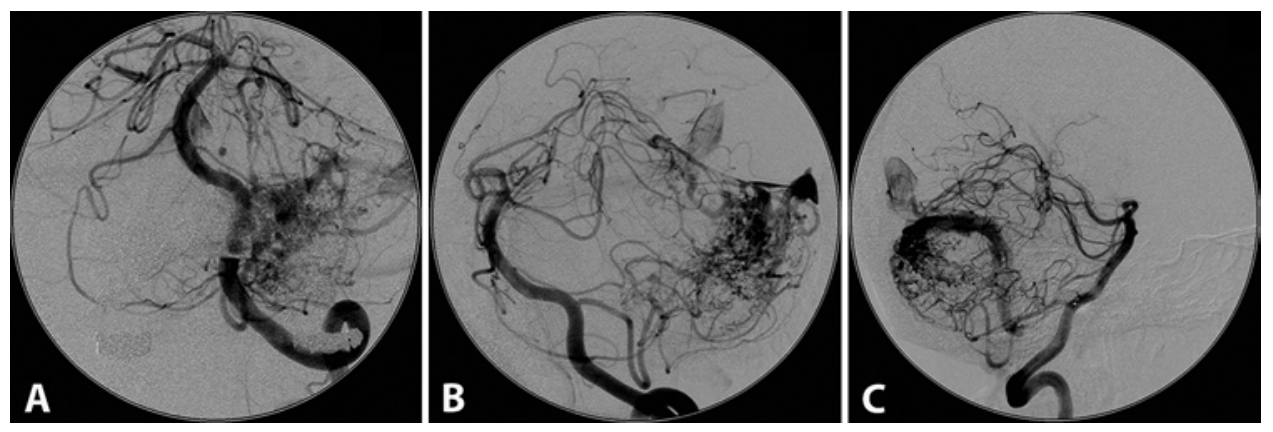

FIG. 2. Preoperative vertebral angiograms (posterior-anterior $[A]$, lateral oblique $[B]$, and lateral $[\mathbf{C}]$ views) illustrate a $3.99-\mathrm{cm}, \mathrm{SM}$ grade III cerebellar AVM located in the left cerebellar hemisphere. This 64 -year-old patient (+1 point) presented in good neurological status with an $\mathrm{mRS}$ score of 2 ( +0 points). After performing preoperative imaging, which showed a deep venous draining cerebellar AVM (+1 point) with active hemorrhaging, the patient was taken for immediate surgical intervention (+1 point). Using our proposed grading system, this patient scores a 3, making it a grade 2 lesion with moderate risk. Complete obliteration was achieved, and this patient experienced a favorable outcome, with his/her most recent 2-year follow-up mRS score $=1$.

variables (emergency surgery, deep venous drainage, and patients $\geq 60$ years old), a greater predictive accuracy was achieved with an AUROC value of 0.737 .

In light of this finding, an ad hoc analysis was performed between each of the variables included in the model, which revealed a number of them were also related to each other. Patients $\geq 60$ years old were more likely to be in a poor PrNS (71\% vs 39\%, p = 0.002), patients with deep venous drainage were more likely to hemorrhage and undergo emergency surgery ( $44 \%$ vs $24 \%$, $p=0.029$ ), patients treated emergently were more likely to present in a poor neurological state (62\% vs $39 \%, \mathrm{p}=0.012)$, and patients $\geq 60$ years old were more likely to hemorrhage and require emergency surgery (65\% vs $28 \%, \mathrm{p}<0.001)$. Consideration was made of combining the risk points of poor PrNS and emergency surgery and having only 1 variable represented. However, we decided against this after finding that the distribution of risk across grades and the model's predictive accuracy were weakened by doing so. In addition, we found that, even after excluding all emergently treated patients, poor PrNS was still associated with poor outcomes $(74 \%, 29 / 39 ; \mathrm{p}=0.016)$.

\section{Prediction Model}

Based on the variables significantly associated with poor outcomes and those that provided the greatest prognostic accuracy, risk points were given to patients depending on the presence of each variable included in the model. The scores were assigned based on the OR value relative to one another obtained during logistic regression analysis (Table 2). This included the following: PrNS $=+2$ points, emergency surgery $=+1$ point, deep venous drainage $=+1$ point, and age $\geq 60$ years $=+1$ point (Fig. 2 ). Scores ranged from 0 (lowest risk) to 5 (highest risk). Scores of 0-1 were classified as grade 1, with 33\% (16/49) of patients experiencing a poor outcome and $0 \%(0 / 49)$ overall mortality; scores of 2-3 as grade 2, with $62 \%$ (24/39) experiencing a poor outcome and $8 \%(3 / 40)$ overall mortality; and scores of $4-5$ as grade 3 , with $83 \%(24 / 29)$ experiencing a poor outcome and 17\% mortality (5/29; Table 3). Three patients did not have the venous drainage type (superficial or deep) available in the medical chart and were not assigned grades; one of these patients died at the time of most recent follow-up so this death could not be included in the grade stratification analysis listed for "overall mortality."

Chi-square analysis indicated that the rate of poor outcomes and overall mortality rates both significantly differed between grades $(p \leq 0.001$ and $p=0.007$, respectively). No difference was present for perioperative mortality $(\mathrm{p}=0.11)$. A visual depiction of patient outcomes by each grading system is provided in Fig. 3. In the logistic regression model, for each successive rise in grade, patients had 3.2 times greater odds of experiencing a poor outcome ( $\mathrm{p}$ $\leq 0.001,95 \%$ confidence interval $[\mathrm{CI}] 1.8-5.5$ ). Compared to grade 1, grade 2 had 3.3 times greater odds and grade 3 had 9.9 times greater odds for experiencing poor outcomes $(p=0.008$ and $p<0.001$, respectively). The predictive prognostic accuracy of the model was found to be "acceptable" by convention, at $72 \%$ (AUROC $=0.72$; Fig. 4). A Hosmer-Lemeshow test was performed to test the goodness-of-fit for the model (observation frequencies separated into groups of 10), showing a good fit with a $\mathrm{p}$ value of 1 .

\section{Literature Review}

The initial search of the literature review produced 869

TABLE 3. Risk-prediction scores per variable and risk grades of model

\begin{tabular}{cccccc}
\hline & & & \% at Risk & \multicolumn{2}{c}{ Mortality Risk $\dagger$} \\
\cline { 5 - 6 } Risk & & Risk & for Poor & & \\
Grade & Points* & Assessment & Outcome (no.) & Periop & Overall \\
\hline 1 & $0-1$ & Low & $33 \%(16 / 49)$ & $0 \%(0 / 49)$ & $0 \%(0 / 49)$ \\
\hline 2 & $2-3$ & Moderate & $62 \%(24 / 39)$ & $3 \%(1 / 39)$ & $8 \%(3 / 39)$ \\
\hline 3 & $4-5$ & High & $83 \%(24 / 29)$ & $7 \%(2 / 29)$ & $17 \%(5 / 29)$ \\
\hline
\end{tabular}

* Points assigned according to the following risk factors: neurological status prior to treatment (yes $=2$ points, no $=0$ ), emergency surgery (yes $=1$ point, no $=0$ ), deep venous drainage (yes $=1$ point, no $=0$ ), and age $\geq 60$ years (yes $=1$ point, no =0).

$\dagger$ Perioperative mortality risk included any deaths that occurred within 30 days after the surgery; overall mortality risk included any deaths that occurred at the time of recent follow-up. 


\section{Patient Outcomes by Grading System}
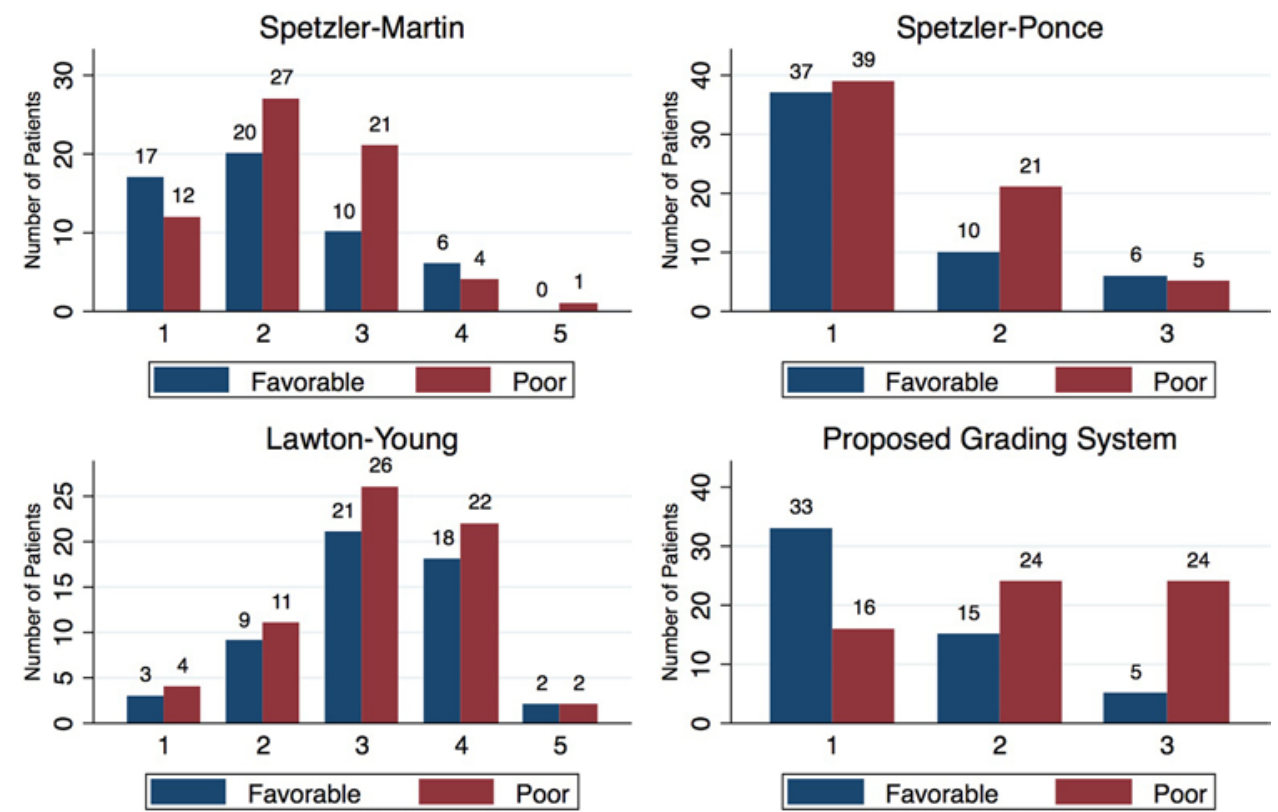

FIG. 3. Patient outcomes by each risk grading classification system for cerebellar AVMs, including the SM, SP, LY, and proposed grading systems. Figure is available in color online only.

articles. Twenty-five articles were eligible for full review after abstract screening. The SM 5-point grading scale, the gold standard for cerebral AVM surgical decisionmaking, was proposed in $1986 .{ }^{39}$ Lawton et al. introduced a supplementary scale in 2010, and in 2011 Spetzler and Ponce proposed a 3-tier system. ${ }^{23,40}$ In 2012, the University of California, San Francisco, Brain AVM Study Group compared the original SM system with the supplementary scale for cerebellar AVMs. ${ }^{35}$ Four articles described anatomical classifications for cerebellar AVMs, designed to aid treatment decision-making; none outlined prognostic parameters. ${ }^{11,16,35,49}$ There are no cerebellar-specific, prognostic, clinically applicable, AVM grading systems present in the literature (Table 4).

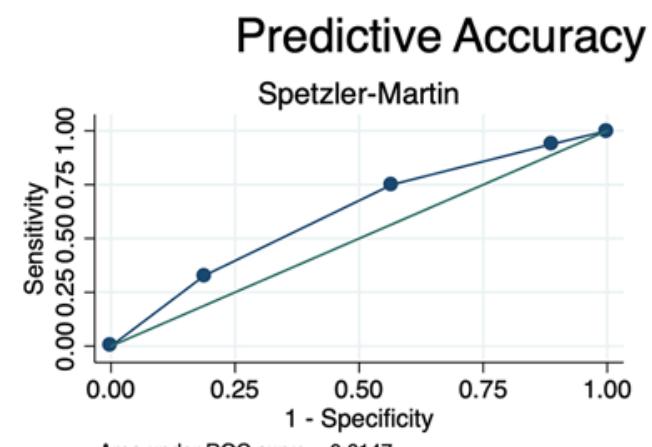

Area under ROC curve $=0.6147$
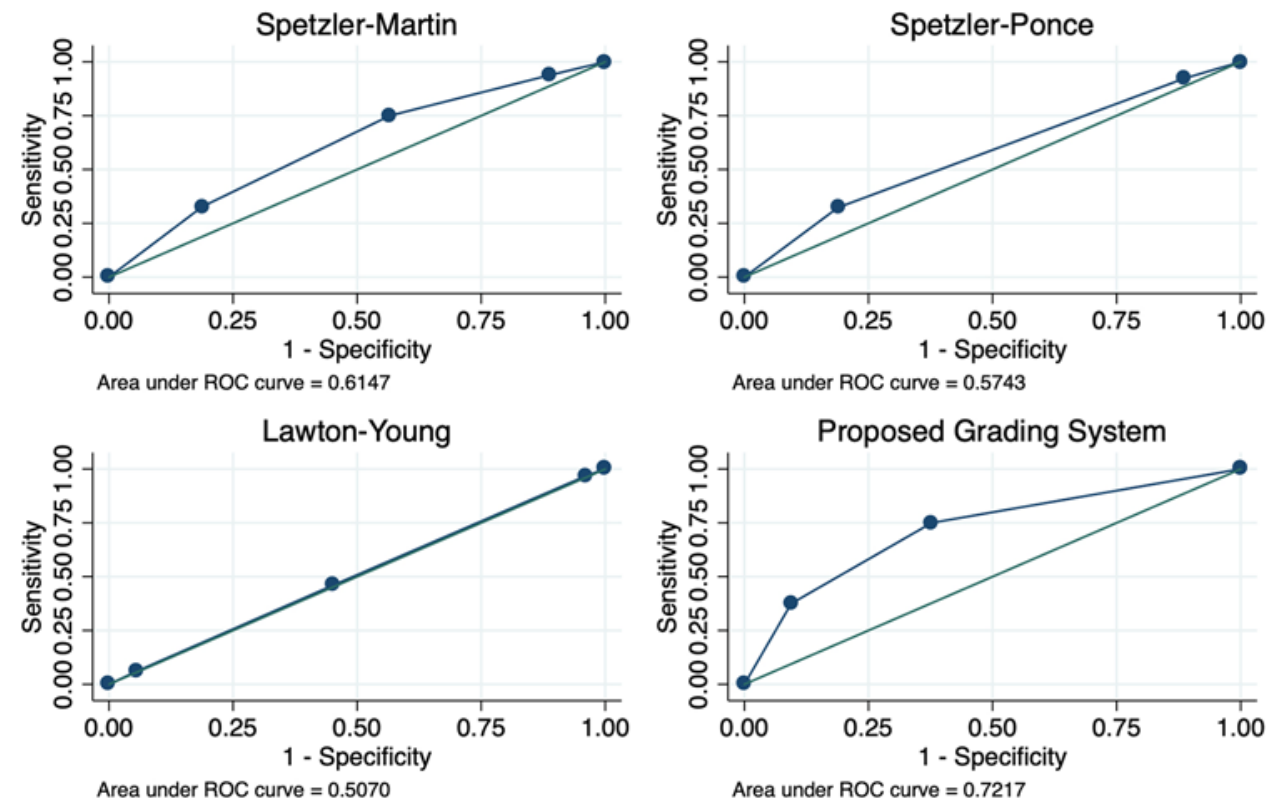

Area under ROC curve $=0.5743$

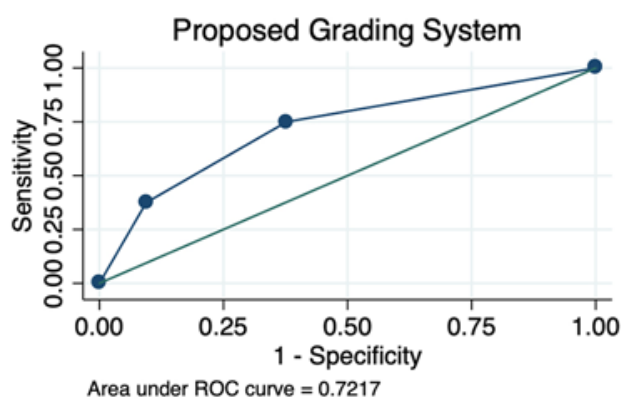

FIG. 4. AUROC listed for each grading system according to predictive accuracy, including the SM, SP, LY, and proposed grading systems. Figure is available in color online only. 
TABLE 4. Literature review results for cerebellar AVM grading systems

\begin{tabular}{|c|c|c|c|c|}
\hline $\begin{array}{l}\text { Study } \\
\text { No. }\end{array}$ & Authors \& Year & Article Title & $\begin{array}{l}\text { Infratentorial } \\
\text { AVM Cases }\end{array}$ & $\begin{array}{l}\text { Grading } \\
\text { System }\end{array}$ \\
\hline 1 & Hung et al., 2018 & $\begin{array}{l}\text { Risk assessment of hemorrhage of posterior inferior cerebellar artery aneurysms in poste- } \\
\text { rior fossa arteriovenous malformations }\end{array}$ & 85 & $\begin{array}{l}\text { Anatom- } \\
\text { ical }\end{array}$ \\
\hline 2 & Lai et al., 2018 & $\begin{array}{l}\text { Posterior fossa brain arteriovenous malformations: clinical features and outcomes of endo- } \\
\text { vascular embolization, adjuvant microsurgery and radiosurgery }\end{array}$ & 63 & No \\
\hline 3 & Tong et al., $2016^{46}$ & Microsurgical outcome of cerebellar arteriovenous malformations: single-center experience & 181 & No \\
\hline 4 & Gong et al., 2015 & Microsurgery for ruptured cerebellar arteriovenous malformations & 67 & No \\
\hline 5 & Robert et al., 2015 & $\begin{array}{l}\text { Anatomic and angiographic findings of cerebellar arteriovenous malformations: report of a } \\
\text { single center experience }\end{array}$ & 59 & No \\
\hline 6 & Abla et al., 2014 & $\begin{array}{l}\text { The natural history of AVM hemorrhage in the posterior fossa: comparison of hematoma } \\
\text { volumes and neurological outcomes in patients with ruptured infra- and supratentorial } \\
\text { AVMs }\end{array}$ & 77 & No \\
\hline 7 & Stein et al., 2014 & $\begin{array}{l}\text { Posterior fossa arterio-venous malformations: current multimodal treatment strategies and } \\
\text { results }\end{array}$ & 53 & No \\
\hline 8 & $\begin{array}{l}\text { Rodríguez-Hernández } \\
\text { et al., } 2012\end{array}$ & $\begin{array}{l}\text { Cerebellar arteriovenous malformations: anatomic subtypes, surgical results, and in- } \\
\text { creased predictive accuracy of the supplementary grading system }\end{array}$ & 60 & Surgical \\
\hline 9 & da Costa et al., 2009 & $\begin{array}{l}\text { Management and clinical outcome of posterior fossa arteriovenous malformations: report } \\
\text { on a single-centre } 15 \text {-year experience }\end{array}$ & 98 & No \\
\hline 10 & Hernesniemi et al., 2008 & $\begin{array}{l}\text { Natural history of brain arteriovenous malformations: a long-term follow-up study of risk of } \\
\text { hemorrhage in } 238 \text { patients }\end{array}$ & 18 & No \\
\hline 11 & Kelly et al., 2008 & Multimodality treatment of posterior fossa arteriovenous malformations & 48 & No \\
\hline 12 & Stapf et al.. 2006 & Predictors of hemorrhage in patients with untreated brain arteriovenous malformation & 71 & No \\
\hline 13 & Stefani et al., 2002 & $\begin{array}{l}\text { Angioarchitectural factors present in brain arteriovenous malformations associated with } \\
\text { hemorrhagic presentation }\end{array}$ & 35 & No \\
\hline 14 & Mast et al., 1997 & Risk of spontaneous haemorrhage after diagnosis of cerebral arteriovenous malformation & 30 & No \\
\hline 15 & Symon et al., 1995 & $\begin{array}{l}\text { Arteriovenous malformations of the posterior fossa: a report on } 28 \text { cases and review of the } \\
\text { literature }\end{array}$ & 28 & No \\
\hline 16 & George et al., 1992 & Arteriovenous malformations of the posterior fossa & 33 & Surgical \\
\hline 17 & Yasargil, 1988 & Microneurosurgery, Vol. IIIB & 58 & Surgical \\
\hline 18 & Drake \& Friedman, 1986 & Posterior fossa arteriovenous malformations & 66 & No \\
\hline 19 & Batjer \& Samson, 1986 & $\begin{array}{l}\text { Arteriovenous malformations of the posterior fossa. Clinical presentation, diagnostic evalu- } \\
\text { ation, and surgical treatment }\end{array}$ & 32 & No \\
\hline 20 & Solomon \& Stein, 1986 & Management of arteriovenous malformations of the brain stem & 12 & No \\
\hline 21 & Samson \& Batjer, 1985 & Arteriovenous malformations of the cerebellar vermis & 15 & No \\
\hline 22 & Fults \& Kelly, 1984 & Natural history of arteriovenous malformations of the brain: a clinical study & 10 & No \\
\hline 23 & Graf et al., 1983 & Bleeding from cerebral arteriovenous malformations as part of their natural history & 11 & No \\
\hline 24 & Matsumura et al., 1977 & Arteriovenous malformations in the posterior fossa & 14 & No \\
\hline 25 & Perret \& Nishioka, 1966 & $\begin{array}{l}\text { Report on the cooperative study of intracranial aneurysms and subarachnoid hemorrhage. } \\
\text { Section VI. Arteriovenous malformations. An analysis of } 545 \text { cases of cranio-cerebral } \\
\text { arteriovenous malformations and fistulae reported to the cooperative study }\end{array}$ & 32 & No \\
\hline
\end{tabular}

\section{Discussion}

The proposed prognostic cerebellar AVM grading system proves to be an effective tool for predicting the risks associated with microsurgical resection. The rate of poor outcomes differs significantly between the risk grades, and the classification system shows an increased risk for poor outcomes (OR 3.01, $\mathrm{p} \leq 0.001)$ and overall mortality $(\mathrm{p}=$ $0.007)$ per grade. Although the predictive accuracy of the model is not excellent, it is acceptable by the standards of convention. In relation to the most widely used prognostic model for AVMs (the SM system), it is not only more accurate (AUROC $=0.72$ vs 0.61 in our study), but also similar to or more accurate than the SM, SP, and LY grading systems for brain AVMs (reported from other studies: AUROC $=0.69-0.726,0.713$, and 0.73, respectively)..$^{20,33,40}$

\section{Outcomes}

Patients with surgically treated cerebellar AVMs experienced poor outcomes at rates much higher than those reported in their supratentorial counterparts. ${ }^{1,23}$ This contrast is illustrative of the unique features of cerebellar AVMs, and again underscores the embedded inaccuracy 
of the SM and LY grading systems. With poor outcome rates of even the lowest-risk grade (33\%) worse than those reported in SM grades III or greater in a high-risk group such as elderly patients (19\%), many would reconsider pursuing surgery. ${ }^{5,23}$ However, cerebellar AVMs must also be viewed in the context of their natural history. Infratentorial AVMs are far less quiescent, presenting often with more than 2 times the rate of hemorrhage. ${ }^{17,19,42}$ Compared to an average annual rupture rate of $2.4 \%$ in brain AVMs, Hernesniemi et al. found infratentorial AVMs neared a rupture rate of $12 \% .{ }^{15}$ Given the high morbidity and mortality rate associated with hemorrhage, a more aggressive treatment has been cited as an appropriate strategy, ${ }^{1,2,27}$ Further corroborating this practice, we found patients were afforded the greatest probability of experiencing a favorable outcome when treated early, prior to intracranial hemorrhage and/or preoperative decline in neurological status. These risk-benefits are not restricted to only surgery and would likely apply to nonoperative methods as well, such as radiosurgery, embolization, or both.

\section{Literature Review}

Lawton et al. (2010) proposed an important supplementary grading scale accounting for age, history of AVM rupture, and nidus compactness. ${ }^{23}$ Subsequently, RodríguezHernández et al. (2012) evaluated the predictive accuracy of the SM system and the Lawton supplementary scale for assessing surgical outcomes associated with cerebellar AVM resection; the SM system showed a statistically significant decline in accuracy to predict cerebellar AVM resection outcomes versus other AVMs. ${ }^{35}$ The authors suggest the supplementary scale has greater predictive accuracy because it is not distorted by the cerebellar anatomy, whereas venous drainage and eloquence have skewed importance with cerebellar AVMs using the SM system. ${ }^{35}$ In 2011, Spetzler and Ponce introduced a 3-tiered system based on the original grading system, in which Class A combines grades I and II, Class B represents grade III, and Class $\mathrm{C}$ combines grades IV and $\mathrm{V} .{ }^{40}$ Although the natural history, presentation, and prognosis of cerebellar AVMs are unique, neither the SM system nor the LY supplementary grading scale was specifically designed for infratentorial AVMs.

\section{Proposed Grading System}

A major difference between this classification and the SM grading system is the decreased relevance of angioarchitectural characteristics. Only deep venous drainage was associated with poor outcomes, comprising 1 of the 5 total risk score points available, while patient age, PrNS, and emergency surgery made up the remaining risk points available. The lack of impact a lesion's size and eloquence had on outcomes in part explains why poor predictive accuracy of the SM grading system has been reported, as was observed in our series. ${ }^{35}$ Clearly, lesion characteristics can be useful for assessing patient risk, but for cerebellar AVMs, clinical factors appear to be most relevant to outcome prediction, as these are not mutually exclusive. This has been a previously cited critique of the SM grading system. ${ }^{37}$ Additionally, during the analysis we found multiple risk factors correlated with one another. These findings reflect upon the complex interplay of angioarchitectural features and patient characteristics and help explain why there was loss of significance for variables in the multivariate regression analysis, along with the limited sample size (a more in-depth analysis and discussion of patient outcomes and lesion characteristics is provided by Nisson et al. on this same patient series ${ }^{30}$ ). Using this risk grading system preoperatively can provide both patients and physicians with a risk estimation for patient outcomes electing into surgery and help better guide treatment strategy.

\section{Deep Venous Drainage}

Our classification shares only one feature with the SM grading system for brain AVMs, which is deep venous drainage. This is fairly intuitive, as Spetzler and Martin described, "no matter how small, [deep venous drainage] further complicates AVM excision." ${ }^{39}$ These veins are prone to bleeding, are more delicate than arteries but also more resistant to cautery, and can retract and bleed into surrounding parenchyma. This has been a known corollary for surgical complications..$^{14,31,37}$ Reports exist of deep venous drainage not being an accurate characterization of cerebellar AVMs. Assessing depth of the veins in cerebellar AVMs can be misjudged given a large proportion drain into the Galenic complex, which is traditionally considered deep for cerebral AVMs but superficial for cerebellar AVMs ${ }^{35}$ Despite this, following the original SM definition, our data indicated a significantly greater risk for poor outcomes in patients with deep venous drainage (OR 2.3, $\mathrm{p}=0.03)$.

\section{Emergency Surgery}

Emergently treated patients showed a strong association with poor outcomes, and thus were given the risk points equal to deep venous drainage. This has been a well-described risk factor in cerebellar AVMs and part of what makes this lesion so dangerous, given its higher than normal rate of rupture in a narrow space near vital structures. ${ }^{3,7,10,44,47}$ This finding highlights the importance of early diagnosis and an aggressive treatment strategy, as operating before AVMs rupture and require emergency treatment offers patients a significantly greater chance of having a favorable outcome with this disease.

\section{Preoperative Neurological Status}

PrNS exhibited the strongest association with patient outcomes. It is well understood that as the extent of CNS injury accumulates, the likelihood of developing a permanent neurological deficit also increases. However, in the acute setting of a hemorrhagic bleed, the extent of CNS injury can be difficult to assess as neurological impairment can be sourced to a number of factors, including hydrocephalus, perihematoma edema, seizures, perihematoma ischemia, and tissue infarction. ${ }^{29}$ For this reason, PrNS may not be completely correlated with the amount of CNS injury a patient has suffered. Yet, our data indicated the presence of an "all or nothing" phenomenon occurring. For instance, the majority $(42 / 57,73.7 \%)$ of patients who presented in poor neurological status remained in 
poor neurological status. Similarly, but to a lesser extent, those who presented in a favorable neurological state also remained in a favorable neurological state $(39 / 63,61.9 \%)$.

This finding suggests the PrNS may, in part, be influencing the ability of neural tissue response to treatment and recovery, i.e., a critical mass-like effect. We provide two hypotheses as to how this could be occurring. First, in the setting of acute CNS injury, both compensatory and deleterious cascades occur. As the extent of injury accumulates, the balance of deleterious cascades begins to outweigh the compensatory mechanisms in an exponential fashion. This can occur through previously described mechanisms, including dysregulated ion gradients, deficiency of energy and metabolites, calcium-mediated cell apoptosis, and myelin-associated inhibitors of axonal regeneration.. Second, the brain has the known ability to reorganize neural synapses, sprout new connections, and migrate new neural cells into the periinfarct cortex. ${ }^{6,28}$ This neural plasticity may become exponentially compromised as neural tissue loss reaches a certain level. Both of these explanations would provide a theoretical framework as to why a stepwise improvement was less frequently observed in the recovery of neurological function and why PrNS was so highly predictive of patient outcomes.

\section{Patient Age}

Patient risk for poor outcomes was not equal among all age groups. Using logistic regression, it was apparent that the risk of a poor outcome increases for patients aged 60 years or older. Tong et al. reported a greater mean age in patients with poor outcomes compared to those with favorable outcomes for cerebellar AVMs $(p=0.018) .{ }^{47}$ Taylor et al. also found age was a risk factor for death from brain AVMs (OR 1.03, $\mathrm{p}=0.006) .{ }^{45}$ An important contributing factor may be comorbidities in older patients, such as hypertension and diabetes, which complicate the disease course and recovery from resection. It may also be related to differences in hemorrhage types with younger patients more often suffering AVM-related intracerebral hemorrhage as opposed to older patients who have spontaneous intracerebral hemorrhage..$^{26,45}$

\section{AVM Size}

A unique feature of the model worth mentioning is that it does not include AVM size. Our data indicated AVM size, whether assessed as a continuous variable or categorically $(>3 \mathrm{~cm})$, carried no associated risk. Tong et al. also found no association with patient outcomes and lesion size $(p=0.08) .{ }^{47}$ We suspect lesion size plays less of a role in affecting the risk for poor outcomes because the volume in the posterior fossa is relatively limited in comparison to the cerebral hemispheres, where AVM sizes can theoretically be much larger. Another pertinent finding was that no difference existed for the rate of emergency surgery between small and large AVM sizes $(p=0.96)$. Because emergency surgery is a known risk factor for poor outcomes, patients with small lesions who underwent emergency surgery would also weaken any potential correlation with AVM size and outcomes.

\section{Eloquence}

Eloquence was not associated with patient outcomes (OR 1.7, $\mathrm{p}=0.40$ ). In previous studies, it has been a risk factor for poor outcomes in both cerebral and cerebellar AVMs. ${ }^{39,47}$ Yet, eloquence has also been considered unreliable for predicting cerebellar AVM risk, as deep nuclei may be the only true eloquent structures in the cerebellum. ${ }^{35}$ Given that deep nuclei primarily have motor regulatory functions, it is likely that in the event damage does occur during AVM resection, the effects are less deleterious to the overall neurological status compared to, for instance, the brainstem nuclei or thalamus of brain AVMs.

\section{Limitations of the Study}

A limitation of this analysis was its retrospective study design. Ideally, a prospectively collected database would be less subject to any potential bias. Given the sample size of 120 patients, assessment of the accuracy of the SM grading system through statistical analysis may not have been fully captured. Lastly, patients were treated at highvolume, specialized surgical centers that may have caused selection bias to occur. At these locations, typically more technically challenging and complex cases are referred for treatment.

\section{Conclusions}

The traditional SM, SP, and LY grading systems are not optimal for the unique AVM lesions of the cerebellum. Our AVM grading system specific for cerebellar lesions is predictive of patient outcomes and can be used to better guide vascular neurosurgeons in clinical decision-making. Further retrospective and prospective studies with large patient samples are needed to validate the predictive capacity of this grading system compared to existing grading scales inclusive of cerebellar AVMs.

\section{References}

1. Abla AA, Nelson J, Rutledge WC, Young WL, Kim H, Lawton MT: The natural history of AVM hemorrhage in the posterior fossa: comparison of hematoma volumes and neurological outcomes in patients with ruptured infra- and supratentorial AVMs. Neurosurg Focus 37(3):E6, 2014

2. Arnaout OM, Gross BA, Eddleman CS, Bendok BR, Getch CC, Batjer HH: Posterior fossa arteriovenous malformations. Neurosurg Focus 26(5):E12, 2009

3. Batjer H, Samson D: Arteriovenous malformations of the posterior fossa. Clinical presentation, diagnostic evaluation, and surgical treatment. J Neurosurg 64:849-856, 1986

4. Bradac O, Charvat F, Benes V: Treatment for brain arteriovenous malformation in the 1998-2011 period and review of the literature. Acta Neurochir (Wien) 155:199_ 209, 2013

5. Burkhardt JK, Lasker GF, Winkler EA, Kim H, Lawton MT: Microsurgical resection of brain arteriovenous malformations in the elderly: outcomes analysis and risk stratification. J Neurosurg 129:1107-1113, 2018

6. Carmichael ST: Cellular and molecular mechanisms of neural repair after stroke: making waves. Ann Neurol 59:735742, 2006

7. da Costa L, Thines L, Dehdashti AR, Wallace MC, Willinsky RA, Tymianski M, et al: Management and clinical outcome of posterior fossa arteriovenous malformations: report on a 
single-centre 15-year experience. J Neurol Neurosurg Psychiatry 80:376-379, 2009

8. Drake CG, Friedman AH, Peerless SJ: Posterior fossa arteriovenous malformations. J Neurosurg 64:1-10, 1986

9. Egawa N, Lok J, Washida K, Arai K: Mechanisms of axonal damage and repair after central nervous system injury. Transl Stroke Res 8:14-21, 2017

10. Fults D, Kelly DL Jr: Natural history of arteriovenous malformations of the brain: a clinical study. Neurosurgery 15:658-662, 1984

11. George B, Celis-Lopez M, Kato T, Lot G: Arteriovenous malformations of the posterior fossa. Acta Neurochir (Wien) 116:119-127, 1992

12. Gong SF, Wang XB, Liao YQ, Jiang TP, He JB, Wang XJ, et al: Microsurgery for ruptured cerebellar arteriovenous malformations. Eur Rev Med Pharmacol Sci 19:2597-2602, 2015

13. Graf CJ, Perret GE, Torner JC: Bleeding from cerebral arteriovenous malformations as part of their natural history. $\mathbf{J}$ Neurosurg 58:331-337, 1983

14. Hartmann A, Mast H, Mohr JP, Pile-Spellman J, Connolly ES, Sciacca RR, et al: Determinants of staged endovascular and surgical treatment outcome of brain arteriovenous malformations. Stroke 36:2431-2435, 2005

15. Hernesniemi JA, Dashti R, Juvela S, Väärt K, Niemelä M, Laakso A: Natural history of brain arteriovenous malformations: a long-term follow-up study of risk of hemorrhage in 238 patients. Neurosurgery 63:823-831, 2008

16. Hung AL, Yang W, Braileanu M, Garzon-Muvdi T, Caplan JM, Colby GP, et al: Risk assessment of hemorrhage of posterior inferior cerebellar artery aneurysms in posterior fossa arteriovenous malformations. Oper Neurosurg (Hagerstown) 14:359-366, 2018

17. Kader A, Young WL, Pile-Spellman J, Mast H, Sciacca RR, Mohr JP, et al: The influence of hemodynamic and anatomic factors on hemorrhage from cerebral arteriovenous malformations. Neurosurgery 34:801-808, 1994

18. Kelly ME, Guzman R, Sinclair J, Bell-Stephens TE, Bower $\mathrm{R}$, Hamilton S, et al: Multimodality treatment of posterior fossa arteriovenous malformations. J Neurosurg 108:11521161,2008

19. Khaw AV, Mohr JP, Sciacca RR, Schumacher HC, Hartmann A, Pile-Spellman J, et al: Association of infratentorial brain arteriovenous malformations with hemorrhage at initial presentation. Stroke 35:660-663, 2004

20. Kim H, Abla AA, Nelson J, McCulloch CE, Bervini D, Morgan MK, et al: Validation of the supplemented SpetzlerMartin grading system for brain arteriovenous malformations in a multicenter cohort of 1009 surgical patients. Neurosurgery 76:25-33, 2015

21. Lai LF, Chen JX, Zheng K, He XY, Li XF, Zhang X, et al: Posterior fossa brain arteriovenous malformations: clinical features and outcomes of endovascular embolization, adjuvant microsurgery and radiosurgery. Clin Neuroradiol 28:17-24, 2018

22. Lawton MT, Hamilton MG, Spetzler RF: Multimodality treatment of deep arteriovenous malformations: thalamus, basal ganglia, and brain stem. Neurosurgery 37:29-36, 1995

23. Lawton MT, Kim H, McCulloch CE, Mikhak B, Young WL: A supplementary grading scale for selecting patients with brain arteriovenous malformations for surgery. Neurosurgery 66:702-713, 2010

24. Mast H, Young WL, Koennecke HC, Sciacca RR, Osipov A, Pile-Spellman J, et al: Risk of spontaneous haemorrhage after diagnosis of cerebral arteriovenous malformation. Lancet 350:1065-1068, 1997

25. Matsumura H, Makita Y, Someda K, Kondo A: Arteriovenous malformations in the posterior fossa. J Neurosurg 47:50-56, 1977
26. Mohr JP, Kejda-Scharler J, Pile-Spellman J: Diagnosis and treatment of arteriovenous malformations. Curr Neurol Neurosci Rep 13:324, 2013

27. Morgan MK, Davidson AS, Assaad NNA, Stoodley MA: Critical review of brain AVM surgery, surgical results and natural history in 2017. Acta Neurochir (Wien) 159:14571478,2017

28. Murphy TH, Corbett D: Plasticity during stroke recovery: from synapse to behaviour. Nat Rev Neurosci 10:861-872, 2009

29. NINDS ICH Workshop Participants: Priorities for clinical research in intracerebral hemorrhage: report from a National Institute of Neurological Disorders and Stroke workshop. Stroke 36:e23-e41, 2005

30. Nisson PL, Fard SA, Meybodi AT, Mooney MA, Kim H, Jahnke H, et al: The unique features and outcomes of microsurgically resected cerebellar arteriovenous malformations. World Neurosurg 120:e940-e949, 2018

31. Pasqualin A, Barone G, Cioffi F, Rosta L, Scienza R, Da Pian $\mathrm{R}$ : The relevance of anatomic and hemodynamic factors to a classification of cerebral arteriovenous malformations. Neurosurgery 28:370-379, 1991

32. Perret G, Nishioka H: Report on the cooperative study of intracranial aneurysms and subarachnoid hemorrhage. Section VI. Arteriovenous malformations. An analysis of 545 cases of cranio-cerebral arteriovenous malformations and fistulae reported to the cooperative study. J Neurosurg 25:467-490, 1966

33. Ren Q, He M, Zeng Y, Liu Z, Liu H, Xu J: Microsurgery for intracranial arteriovenous malformation: long-term outcomes in 445 patients. PLoS One 12:e0174325, 2017

34. Robert T, Blanc R, Ciccio G, Redjem H, Fahed R, Smajda $\mathrm{S}$, et al: Anatomic and angiographic findings of cerebellar arteriovenous malformations: report of a single center experience. J Neurol Sci 358:357-361, 2015

35. Rodríguez-Hernández A, Kim H, Pourmohamad T, Young WL, Lawton MT: Cerebellar arteriovenous malformations: anatomic subtypes, surgical results, and increased predictive accuracy of the supplementary grading system. Neurosurgery 71:1111-1124, 2012

36. Samson D, Batjer H: Arteriovenous malformations of the cerebellar vermis. Neurosurgery 16:341-349, 1985

37. Schaller C, Schramm J, Haun D: Significance of factors contributing to surgical complications and to late outcome after elective surgery of cerebral arteriovenous malformations. J Neurol Neurosurg Psychiatry 65:547-554, 1998

38. Solomon RA, Stein BM: Management of arteriovenous malformations of the brain stem. J Neurosurg 64:857-864, 1986

39. Spetzler RF, Martin NA: A proposed grading system for arteriovenous malformations. J Neurosurg 65:476-483, 1986

40. Spetzler RF, Ponce FA: A 3-tier classification of cerebral arteriovenous malformations. Clinical article. J Neurosurg 114:842-849, 2011

41. Stapf C, Mast H, Sciacca RR, Choi JH, Khaw AV, Connolly ES, et al: Predictors of hemorrhage in patients with untreated brain arteriovenous malformation. Neurology 66:1350-1355, 2006

42. Stefani MA, Porter PJ, terBrugge KG, Montanera W, Willinsky RA, Wallace MC: Angioarchitectural factors present in brain arteriovenous malformations associated with hemorrhagic presentation. Stroke 33:920-924, 2002

43. Stein KP, Wanke I, Schlamann M, Dammann P, Moldovan AS, Zhu Y, et al: Posterior fossa arterio-venous malformations: current multimodal treatment strategies and results. Neurosurg Rev 37:619-628, 2014

44. Symon L, Tacconi L, Mendoza N, Nakaji P: Arteriovenous malformations of the posterior fossa: a report on 28 cases and review of the literature. Br J Neurosurg 9:721-732, 1995

45. Taylor B, Appelboom G, Yang A, Bruce E, LoPresti M, 
Bruce S, et al: Underlying effect of age on outcome differences in arteriovenous malformation-associated intracerebral hemorrhage. J Clin Neurosci 22:526-529, 2015

46. Tong X, Wu J, Lin F, Cao Y, Zhao Y, Wang S, et al: Microsurgical outcome of cerebellar arteriovenous malformations: single-center experience. World Neurosurg 95:469-479, 2016

47. Tong X, Wu J, Lin F, Cao Y, Zhao Y, Wang S, et al: Risk factors for subsequent hemorrhage in patients with cerebellar arteriovenous malformations. World Neurosurg 92:47-57, 2016

48. van Beijnum J, van der Worp HB, Buis DR, Al-Shahi Salman R, Kappelle LJ, Rinkel GJ, et al: Treatment of brain arteriovenous malformations: a systematic review and meta-analysis. JAMA 306:2011-2019, 2011

49. Yasargil MG: Microneurosurgery, Vol IIIB. New York: Thieme Medical Publishers, 1988

\section{Disclosures}

The authors report no conflict of interest concerning the materials or methods used in this study or the findings specified in this paper.

\section{Author Contributions}

Conception and design: Nisson, Fard, Walter, Johnstone, Tayebi Meybodi, Dumont, Lemole. Acquisition of data: Walter, Mooney, Lang, Kim, Jahnke. Analysis and interpretation of data: Nisson, Mooney, Tayebi Meybodi, Roe. Drafting the article: Nisson, Tayebi Meybodi. Critically revising the article: Lawton, Nisson, Fard, Mooney, Tayebi Meybodi, Dumont, Lemole, Spetzler. Reviewed submitted version of manuscript: Lawton, Nisson, Fard, Walter, Johnstone, Tayebi Meybodi, Dumont, Lemole, Spetzler. Statistical analysis: Nisson, Tayebi Meybodi, Roe. Administrative/technical/ material support: Walter, Tayebi Meybodi. Study supervision: Lawton, Tayebi Meybodi, Dumont, Lemole, Spetzler.

\section{Supplemental Information}

\section{Online-Only Content}

Supplemental material is available with the online version of the article.

Supplemental Table 1. https://thejns.org/doi/suppl/10.3171/ 2018.12.JNS181677.

\section{Correspondence}

Michael T. Lawton: Barrow Neurological Institute, Phoenix, AZ. michael.lawton@barrowbrainandspine.com. 